\title{
Management of newly diagnosed atrial fibrillation in an outpatient clinic settingpatients perspectives and experiences
}

Lars Thrysoee, Anna Strömberg, Axel Brandes and Jeroen Hendriks

The self-archived postprint version of this journal article is available at Linköping University Institutional Repository (DiVA):

http://urn.kb.se/resolve?urn=urn:nbn:se:liu:diva-145787

N.B.: When citing this work, cite the original publication.

Thrysoee, L., Strömberg, A., Brandes, A., Hendriks, J., (2018), Management of newly diagnosed atrial fibrillation in an outpatient clinic settingpatients perspectives and experiences, Journal of Clinical Nursing, 27(3-4), 601-611. https://doi.org/10.1111/jocn.13951

Original publication available at:

https://doi.org/10.1111/jocn.13951

Copyright: Wiley (12 months)

http://eu.wiley.com/WileyCDA/ 


\section{Management of Newly Diagnosed Atrial Fibrillation in an Outpatient}

\section{Clinic Setting - Patient's perspectives and experiences}

Lars Thrysoee Clinical Nursing Researcher, RN, MLP, Ph.D. Assistant professor, ${ }^{1}$ Anna

Strömberg RN, Professor ${ }^{2}$, Axel Brandes Associate Professor MD DMSc FESC ${ }^{1}$, Jeroen Hendriks RN PhD NFESC 2,3

${ }^{1}$ Department of Cardiology, Odense University Hospital and Institute of Clinical Research, University of Southern Denmark, Odense, Denmark

2 Department of Medical and Health Sciences, Linköping University, Linköping, Sweden

${ }^{3}$ Centre for Heart Rhythm Disorders, University of Adelaide, Royal Adelaide Hospital, South Australian Health and Medical Research Institute, Adelaide, Australia

\section{Acknowledgement}

Thanks to patients and health care professionals for their participation in the study

\section{Funding}

The project is funded by Novo Nordisk Foundation

\section{Conflict of interest}

None to declare

\section{Corresponding author}

Lars Thrysoee

Assistant Professor, Clinical Nursing Researcher, PhD, MLP, RN

Department of Cardiology, Odense University Hospital

Entrance 20, 4th floor,J.B. Winsløwsvej 4

5000 Odense $\mathrm{C}$

Denmark

lars.thrysoee@rsyd.dk

Phone: +4524637797 


\section{ABSTRACT}

Aims: To gain in-depth knowledge on patients' experiences of the consultation processes at a multidisciplinary atrial fibrillation outpatient clinic in a university hospital in Denmark.

Background: Atrial fibrillation is the most common arrhythmia associated with morbidity and mortality if not diagnosed and treated as recommended by guidelines. Patients with newly diagnosed atrial fibrillation should be managed in an outpatient setting which includes medical examination, patient education and decision making on medical therapy.

Design: This is a qualitative study including 14 patients referred from general practitioners newly diagnosed with atrial fibrillation, ranging from being asymptomatic to patients having mild to severe symptoms.

Methods: Data was generated in 2013-2015 using participant observation during each consultation, followed by individual interviews post-consultation.

Results: Patients were referred with limited information on AF and knowledge about the management consultation procedures. The consultations were performed in a professional way by a heart rhythm specialist as well as by nurse with emphasis on the medical aspects of atrial fibrillation. The understanding that atrial fibrillation is not a fatal disease in itself was very important for patients. At the same time, visiting the clinic was overwhelming and information was difficult to understand and patients found it difficult to be involved in decision-making.

Conclusions: This study indicates that patients were uncertain on AF before as well as after consultation. The communication was concentrated on the medical aspects of atrial fibrillation and visiting the clinic was an overwhelming experience. 
Patients had difficulty understanding what atrial fibrillation was and why they were treated with anticoagulation, and that it was a lifelong treatment.

Relevance for clinical practice: This study demonstrates some lack of patientcentred care and an absent of tailored patient AF-related education. Furthermore, the study highlights the need and importance of active patient involvement.

Keywords: atrial fibrillation, clinical management, multidisciplinary care, outpatient clinic, patient experiences 


\section{BACKGROUND}

Atrial Fibrillation (AF) is the most common cardiac arrhythmia and is associated with increased morbidity and mortality (Camm et al. 2010). It is estimated that the incidence of AF will at least double by the year 2050 (Broge 2011, Naccarelli et al. 2009, Rich 2009, Stewart et al. 2004) reaching epidemic levels (Chugh et al. 2014) and complications will expand dramatically. Poor guideline adherence in the management of AF (Estes et al. 2011), will influence the patients' AF symptom burden' (Bohnen et al. 2011) and increase the economic burden of the health care system (Ringborg et al. 2008, Savelieva \& Camm 2008, Stewart et al. 2004) There is a wide variety in the way patients experience AF symptoms ranging from completely asymptomatic patients to those with a complex burden of severe physical symptoms, and related mental and social consequences (Camm et al. 2010, Deaton et al. 2003, Kellen 2004) which is associated with increased uncertainty resulting in poor mental and general health (Kang 2005). AF symptoms include palpitations, shortness of breath, fatigue, dizziness, and syncope (January et al. 2014). Symptoms can be misinterpreted by patients as well as by health care providers as not disease-related and caused by other conditions such as ageing, physical deconditioning or stress, resulting in delay of diagnosis and treatment (McCabe et al. 2014).

Patients with AF have also been found to have a significantly lower Health-related Quality of Life (HRQOL) and more symptoms of anxiety and depression compared to the general population and to patients with other heart diseases (Thrall et al. 2006, Thrall et al. 2007). This might be caused by delayed diagnosis, lack of 
caring support to cope with the emotional burden of AF and distress caused by unpredictable AF symptoms and lack of counselling regarding the nature of $A F$ and self-management (McCabe et al. 2011). AF accounts for one third of all hospital admissions for arrhythmia (Fuster et al. 2006), which is the primary cost driver in AF management (Reynolds et al. 2007) in North America as well as in Europe (Chugh et al. 2001, Tsang et al. 2003). Furthermore, Reynolds et al. (Reynolds et al. 2010) compared symptom frequency and HRQOL between hospitalised AF patients versus non-hospitalised. They found that increased symptom frequency and severity as well as reduction in $\mathrm{HRQOL}$ were associated with hospitalisation.

An intervention to contribute to reduce hospitalisation significantly in these patients is to strengthen outpatient services for elective treatment and short-term follow-up (Conti et al. 2012). A nurse-coordinated outpatient clinic might contribute to this in terms of reducing waiting times and number of appointments, improving patients`experiences of arrhythmia services, and reducing healthcare costs (Wise \& Annus 2013). Furthermore, a Dutch study demonstrated that a nursecoordinated AF-clinic had a positive impact on guideline adherence (Hendriks et al. 2010). This effect is also shown in a subsequent study comparing a nurse-led AF-clinic with usual care (Hendriks et al. 2012). In this study, Hendriks et al. demonstrated that a nurse-led AF clinic, improved patient management, and clinical outcomes in terms of reduced cardiovascular hospitalisations and death while being a cost-effective management approach (Hendriks \& Strömberg 2015). Little is known from the literature about how patients with newly detected AF are informed about AF and its treatment options in an outpatient clinic setting and 
what patients' attitudes and believes are towards participation in treatment decisions. Thus, the purpose of this study was to describe newly referred AF patients' experiences on the consultation processes at an AF-clinic.

\section{METHODS}

This is a qualitative study with a descriptive design following an ethnography approach which is exceptional for studying processes and relationships among people and events during time (Jorgensen 1989). The researcher was an observing participant by following the patients in the AF-clinic and in that way, the researcher gained insight in what took place pre-consultations as well as during the consultations and after-consultations. The researcher made fieldnotes (Spradley 1980) on who were involved and how they reacted, when and where activities happen and how activities influence on the patients (Jorgensen 1989). Furthermore, semi-structured individual interviews (Kvale 2007, Körner 2010) with patients were performed post-consultations.

\section{Study participants}

Participants were recruited between $2013-2015$ and were eligible for the study if AF was documented on ECG, they were referred from a GP practice for the first time due to newly detected AF, were 18 years of age or older, and were able to understand and speak Danish. Patients were recruited prior to their first consultation in the outpatient clinic. Patients were excluded if they had any comorbidity which was unsatisfactorily treated, if they had a pacemaker within 
three months before the consultations or if they were discharged after the first visit in the AF-clinic.

\section{Setting}

The study took place in an AF outpatient clinic at a large university hospital in Denmark. The multidisciplinary team (Fridlund et al. 2015, Körner 2010) at this clinic consists of a cardiologist who is a specialist in heart rhythm diseases (HRS) and two AF-specialized nurses, who have a wealth of experience in AF and have worked with AF-patients for several years. Nurses and cardiologist form the AF treatment team, each with specific tasks and responsibilities. The organisation of care in the AF-clinic was as follows: at the first patients had an appointment with the HRS. The HRS performed physical and medical examinations (ECG, echocardiography and medical history), questioned the patients for their signs and symptoms, informed the patients about AF and initiated medical treatment. At follow-up consultations, patients were seen by the specialized AF nurse. The nurse has more time talking with the patients, focusing on ECG control, burden of AF-symptoms, the patients' response to treatment and how patients were handling their symptoms and treatment. The nurse explained medications, and changed medical treatment if necessary after consultation with the HRS. The nurse coordinated the care, decided for how long patients were followed in the AF-clinic and when patients were discharged to follow- up by GP. If the patient had more than one consultation with a nurse, patients did not always consult the same nurse than previous. Each consultation took approximately 30 to 45 minutes. 


\section{Data collection}

Data was collected by following patients pre-consultation in the waiting area as well as during every consultation at the AF-clinic as well as by semi-structured individual interviews post-consultations.

The researcher followed each patient during every consultation in the clinic from arrival to leaving the hospital after consultation. Fieldnotes in terms of condensed notes (Spradley 1980) were taken as close to the situation as possible. The following variables were recorded: time of patient arrival to the waiting area, time when consultation started, time for procedures and activities (i.e.

echocardiography, ECG, information about AF and treatment) during consultation and time when consultation ended.

Fieldnotes were taking in the waiting area before each consultation regarding the patients' expectations on the consultation and thoughts about his / her illness. During each consultation, the researcher was passively observing and taking fieldnotes on how related activities were performed, on how the patient was placed in the room, how the patient and the HRS / nurse reacted on each other and how the verbal as well as the nonverbal communication between the patient and the HRS or the nurse proceed. After the consultation, the researcher questioned the patients on their experiences during the consultations. Afterwards, the condensed notes were expanded with missing information, as recommended in the literature (Spradley 1980).

At final follow-up of consultation periods in the AF-clinic, a semi-structured digitally recorded interview (Kvale 2007) took place in a quiet room at the hospital or in the home of the patient. The interview focussed on patients`experiences of 
consultations in the AF-clinic and how it affects their way of handling AF. Data collection was performed by the first author, who was not involved in the delivery of care to patients that participated in the study.

\section{Analysis}

The transcribed fieldnotes and interviews appeared as text which were analysed and interpreted in a phenomenological-hermeneutical approach based on Paul Ricoeur's interpretation theory (Ricoeur 1976). The analysis took place in a backwards and forwards process between understanding and explanation of the meaning of the text. The analysis was carried out at three analytical steps: 1) naïve reading, 2) structural analysis and 3) critical interpretation and discussion. Thus, the text was opened up for a possible understanding of what the meaning in the transcribed interviews and fieldnotes refer to in the consultation situation (Ricoeur 1973).

Naive reading is the first conjecture of the analysis (Dreyer \& Pedersen 2009, Ricoeur 1976). The transcribed fieldnotes and interviews were read several times in a non-judgemental way in order to grasp the meaning of the text as a whole. What did the text say at first glance about how participants experienced the consultation processes and how they handled their illness?

Structural analysis intends to clarify the dialectics between the naïve reading and the interpretation of what the text is about, moving from units of meaning (what the text is saying) to units of significance (what is the text speaks about) (Dreyer \& Pedersen 2009). An example on how the main theme "Visiting the clinic - an overwhelming experience" emerged is illustrated in table 2. 
The transcribed fieldnotes and interviews were read and reread, and parts of the text were enhanced when there was a reference to how the consultations progressed, how interactions with health care professionals proceeded and were experienced, and how thoughts of illness were expressed. In this analysis step, main themes and subthemes related to the purpose of the study were generated. Results of the structured analysis were subsequently critically interpreted and discussed by the authors. The intention of critical interpretation and discussion was to move from an understanding of participants' experiences to a possible understanding of what their experiences refers to in the consultation processes in the AF-clinic and in the patients thoughts of living with AF. The critical interpretation and discussion appears in the discussion section of this article where the naive reading, the findings from fieldworks and interviews, and results from the literature review form a comprehensive understanding of the generated data.

\section{Ethical considerations}

The study was reported to the Danish Data Protection Agency (no. 2008-58-0035) and conducted according to the principles outlined in the Helsinki Declaration (Association 2013). All participants gave written informed consent. We applied for Ethical approval but formal approval from the local ethical committee was not required according to legislation in Denmark.

\section{RESULTS}




\section{Participants}

As illustrated in Table 1, fourteen patients (7 males and 7 females), aged between 40 years and 82 years (mean: 68.2, \pm 10.2 ) were consecutively included from February 2013 to September 2014. Symptoms of AF were asymptomatic (3) or reported mild or severe palpitation and dyspnoea. Types of AF: Paroxysmal (5), persistent (1), permanent (8); the total number of consultations with the HRS $t$ and the nurse ranged from 2 to 5 , with an average of 3 .

\section{Naive reading}

The overall impression of the naive reading was that although patients were very satisfied with the consultation in the AF clinic, it did not lead to a clear understanding of $A F$ and why they received the suggested treatment. The patients described uncertainty what causes the AF symptoms and why they were treated with oral anticoagulation medicine. They adhered to the prescribed treatment, but did not understand the effects of the medications. Furthermore, it was difficult for them to explain AF in their own words. The most important value of the consultations was that patients were told that they would not die from AF in itself.

The results from the structured analysis of the transcribed fieldnotes and interviews indicate similarities in the results. These results could be associated with certain themes and subthemes (table 2) and sequenced according to the patient journey in the AF-clinic. The themes are: "Uncertainty about the atrial fibrillation before first consultation"; "Focus on the medical aspects of atrial fibrillation"; "Atrial fibrillation is no fatal disease"; "Professionalism and 
competence in the care of atrial fibrillation", and "Visiting the clinic - an overwhelming experience".

\section{Uncertainty about the atrial fibrillation before first consultation}

In some patients, AF was detected by coincidence, when consulting a GP for a regular control of their diabetes or hypertension. Patients were surprised that they had a heart disease and describe the AF diagnosis as shocking. For other patients, mild or more severe symptoms had been interpreted driven by age, poor lifestyle or lack of fitness:

FJ: "I was just sitting quietly not doing anything and then something suddenly happened. At the first time I thought it was caused by smoking a pipe, because that could raise the pulse. I refrained from smoking for a week or so to see if it stopped but nevertheless it came back. This was dammed surprisingly - without any form of physical activity... And then I consulted my GP".

Almost none were told anything about AF by their GP. They were referred to the outpatient clinic because of "something with my heart rhythm" and only one patient had searched for information before the first consultation in the AF-clinic. Furthermore, patients were not informed about procedure in the AF-clinic beforehand. Therefore patients often did not discuss with their relatives how to prepare for the first visit to the AF-Clinic (e.g. important questions) and also they did not know what to expect.

A patient and her husband said:

$\mathrm{HN}$ : "We [patient and her husband] did not know, what was going to happen during the first consultation. We expected an examination, but we did not know how."

Another patient expressed: 
JT: "It was difficult to prepare not knowing what was going to happen during consultation and when consultation in the AF clinic ended"

\section{Focus on the medical aspects of atrial fibrillation}

The medical examination at the first visit by HRS lasted on average 35 minutes. Finally patients were given information about the AF and about decision making of medical treatment for the last 10 to 15 minutes.

One patient expressed his thoughts after the first consultation like this:

$\mathrm{NH}$ : "It was very difficult to understand and remember what was told and what was decided during the consultation. I needed to visit my GP to have more information about what it all means"

The nurses carried through consultation in almost the same way as physicians by starting consultation doing an ECG and afterwards talked with the patient how he / she handled the treatment, if there were any side-effects, and how AF symptoms affected the daily life. Nurses did not asked patients about their experiences of their previous consultation and how patients react on having a disease as AF and to be treated with anticoagulation.

Before ending each consultation, patients were asked whether they have any questions. Almost none of the patients had any question and one patient mentioned afterwards that "It was difficult to know what I should ask for". Questions concerning AF and treatment appeared while patients were at home and when relatives asked what had happened.

\section{Atrial fibrillation is no fatal disease}

Prior to the first consultation, severe symptoms with episodes of rapid palpitation unleashed fear of dying and concerns on whether the heart was damaged over 
time or could wear out. Metaphors such as "a machine going too fast and needing oil" or "the machinery" or "tick-tick nearly stops" were used. Their situation was compared to friends and relatives who have a heart disease without knowing what kind of disease it is. A patient expressed it like this:

AH: "I had been told horrible stories and was really afraid that my heart would be damaged because of the [AF] attacks"

Recurrences had a disabling impact on the daily life and could appear when patients were in rest while reading or watching TV. They did not know how to react. The patient cited below had several episodes for a longer period without consulting a GP:

$\mathrm{KL}$ : "It [the attack] continued during the whole night, and I did not dare to fall asleep."

Some had an episode during exercise:

FJ: "I was playing badminton, and I made - yes I don't think that Peter Gade could have made it better - a dream stroke and we won the game. And at the same time, I had an attack and thought: damned - now it is your turn [to die]"

HRS as well as nurses reassured the patients that they would not die from AF in itself and information on risk factors was focusing about bleeding risk and how to handle this. The knowledge that their arrhythmia was not fatal was crucial and important in coping to their situation. A patient expressed it like this concerning information on not going to die because of AF:

JT: "Knowing that I was not going to die because of AF was the most important information from the consultation. To be referred to the AF clinic was the best that could happen for me" 
The medical examination (ECG, echocardiography and medical history) by the HRS lasted on average 35 minutes and was described as profound. The HRS was seen as very competent and meticulous as well as the nurses in the follow-up consultations. HRS and nurses handled the consultation in a confidence-building way for most of the patients, taking their situation seriously and took sufficient time for the consultations. A patient expressed it like this:

EH: "When I left the first consultation, I had a feeling that he knew a lot about this disease. But he also listened to what it did to me. And it made a big difference. You left with a feeling of how my situation was maintained or noted or however - that's me"

And another patient says:

$\mathrm{JH}$ : "It was very confident to be examined by a person who was competent and did it in a meticulous way".

The patients were being seen by the HRS as well as the nurses who took the time to listen to the patients and there was no rush during consultations. Afterwards, $\mathrm{AF}$ recurrencies with palpitations and other AF-symptoms seem to result in less concern compared to pre-consultation.

\section{Visiting the clinic - an overwhelming experience}

The medical examinations and the extensive information on AF in a complex situation during were difficult for patients to follow and to understand. At the same time, most patients were elderly and some were using a hearing aid and the physician was talking fast and for the most of the time.

After the first consultation, some patients were confused regarding AF as a condition, the AF diagnose, and the prescribed therapy. 
FJ: "When I came home, my wife asked: Why do you get this medicine and why do you get this other medicine? I really can't explain - it has something to do with my heart. [pause] My wife sees things as bigger problems whereas I [pause] well.... I do have a more relax way of handling the situation... Looking back, I would have preferred, that my wife had participated during the first consultation"

Before the second consultation asymptomatic patients expressed that they hoped AF was cured by treatment with anticoagulation and that they could stop taking these medications, given that they were in sinus rhythm again. Symptomatic patients hoped that the examination (e.g. ECG recording) would show a reduction of $\mathrm{AF}$ due to the treatment, even in the case when they were only treated with anticoagulation, and that they could reduce or terminate the medical treatment. Most patients did not understand the association between AF, anticoagulation and stroke and how AF was a lifelong disease. Some of them did not take the medicine as prescribed for various reasons, e.g. having discomfort linked to medicine altogether, forgetting to take the medicine several times and not redeeming the prescription.

Some patients received a brochure about treatment at the end of the first consultation - others did not. They did not read the brochures afterwards, and there was no follow up on the contents in the brochures by the nurses. During the final interview, almost none could describe in own words, what AF is and why medical treatment was prescribed as it was. They just took the medicine without knowing details about how it would affect their disease.

\section{DISCUSSION}


AF is a complex condition and its association with underlying cardiovascular comorbidities and risk factors makes the treatment a very complex process. One can imagine that it is difficult for patient to understand this process and to understand the association between $\mathrm{AF}$, medical treatment and risk factors. In this study we examined the effect of a specialized outpatient AF-clinic on a large university hospital in Denmark by following a group of patients during the consultations. Our study showed that providing extensive information on AF in a complex situation made it difficult for patients to understand AF and why treatment (especially anticoagulation) was prescribed. Furthermore, our study shows how an AF clinic provides structured care in a professional and confidence-inspiring way. Communication between health care professionals and patients was dominated by medical aspects with patients having a more passive role. The most valued information for the patients was to hear, that their $\mathrm{AF}$ was not a fatal condition intrinsically. Nevertheless, mortality does not only relate to AF but also to underlying (cardiovascular) co-morbidities and risk factors (Kirchhof et al. 2016), and these issues were not discussed with the patients.

The AF service as described in this paper can be interpreted as an integrated approach to care, which facilitates guideline-adherent management for $\mathrm{AF}$ patients provided within a multidisciplinary team approach, with the main goal to improve outcomes. This is in line with recommendations from the recently published ESC guidelines on the management of AF stating that structured organisation of care and follow-up should be considered in all patients with AF, to improve guideline adherence but also to keep patients out of hospital and reduce mortality. Guidelines advocate for a patient-centred approach where patients 
should be placed in a central role in the decision making, in order to individualize the care to patient needs and preferences and also improve adherence to longterm treatment. Before patients can take these important roles, tailored patient education is of utmost importance and recommended in all phases of $\mathrm{AF}$ management (Kirchhof et al. 2016). However in this study it was demonstrated that this was not completely the case. When patient's understanding of their condition is lacking, it is difficult for patients to understand symptoms and participate in their own care process is, as demonstrated in this study.

Furthermore, our research showed how visiting the AF-clinic was overwhelming with complicated information in a short time. Overwhelming information may increase the risk of not understanding the effect of medical treatment and reduced patient involvement in decision making about choice of anticoagulation treatment. A consequence may be that patients do not take anticoagulation as described, with potential ischaemic stroke (Berian \& Livingston 2015) or brain haemorrhage (Deitelzweig et al. 2013, Vestergaard et al. 2016) as a fatal complication. According to a report from the Wold Health Organisation in 2003, non-adherence is caused by e.g. social economic conditions or influenced by several factors in health care system or in patient related factors. The consequences of poor adherence are poor health outcome and increased health costs (Sabaté 2003). During the interviews, the patients in our study expressed their concerns about taking medication altogether. A review from 2005 concludes that non-adherence is not due to failure of patients, doctors, or system but a general reluctance of patients taking medicine (Pound et al. 2005). 
The recent ESC guidelines on the management of $\mathrm{AF}$ recommend patient involvement in decision making about medical treatment since it has a positive effect on adherence (Kirchhof et al. 2016). It is crucial that patient involvement requires patient education as well as attention to interpersonal aspects in the consultation situation (White et al. 2013). Active patient involvement relates to how patients are able to prepare before decision-making, how they receive information during consultation which can improve patients' understanding of their own situation and how they are able to follow up consultations with health care professionals (Siouta et al. 2015). In our study, patients were not so much involved in their care. Active involvement requires health care professionals that invite patients for active participation. Most patients in our study did not ask for further information at the end of consultations, even though they were invited and even though they did not understand the link between AF, stroke, and anticoagulation. They took the medicine as prescribed and did not want to be involved in decision-making about treatment. As shown by Borg Xuereb et al. (Borg Xuereb et al. 2012), some patients want to be an active part of treatment decision-making, while others are satisfied to leave it to the expertise of the health care professionals. Health care professionals as well as patients need to become more comfortable and confident with decision-making, including medical evidence (objective) as well as life context for patients (social and subjective world) to ensure the best treatment decisions (Kirchhof et al. 2016, Martin et al. 2005). A Swedish study shows that patients need a sense of trust in the care they received as well as feeling secure by patient-centred communication in terms of a patient involving approach during consultations (Siouta et al. 2015). Patient- 
centred care empowers patients and respect patient values, preferences and needs (Kirchhof et al. 2016). In some way, this is opposite the tendency over the last decades with more task-oriented consultations, where patients talk less, while health care professionals provide medical information (Butalid et al. 2014). The same tendency was present in our study. Consultations were handled in a professional way by the HRS and the nurses following a medical and disease approach in the communication between them and the patients. Patients were more or less silent and did not talk about their thoughts of AF and their fear of dying before the first consultation. A Dutch study shows, how nurses performed outpatient consultation based on a conventional medical model of medical history taking. The authors conclude that it is not beneficial for self-management support, when little attention is paid on patients' perspective on their illness (Ter MatenSpeksnijder et al. 2016). According to Kleinman et al. (Kleinman et al. 2006), there is an important distinction between disease and illness. Disease focuses on malfunction biological processes in patients whereas illness focuses on personal reaction to the disease. There needs to be more attention on the patient's perspective of his or her situation as an illness, using questions such as: "What do you think sickness does to you?" or "What do you think caused your problem?" In that way, clinicians show concerns about, how patients react to sickness and how it affects patients daily life (Kleinman et al. 2006).

Furthermore, of the organisational level integrated care with a patient-centred view (Kodner \& Spreeuwenberg 2002) and an interdisciplinary approach (Körner 2010) supports nurses and HRS working closely together and form an AF treatment team. Consequently, patients are educated and involved in their care 
process and form an active partner in shared decision- making on treatment, care and lifestyle aspects of AF (Hendriks \& Strömberg 2015).

In our study, patients with asymptomatic AF detected by a coincidence by their GP were very surprised at having AF. Asymptomatic patients seemed to have difficulties accepting AF as a chronic disease and hoped treatment would cure AF. The GP is important in detecting AF, and the ECS guidelines (Kirchhof et al. 2016) demonstrate the importance of screening in older populations using either pulse palpation or short-term ECG to detect undiagnosed or silent AF (Kirchhof et al. 2016). Patient education is recommended in all phases of AF management to support patients' perception of AF and to improve management (Kirchhof et al. 2016). As a consequence, patients should be informed about AF and how medical examination takes place at the AF outpatient clinic before the first consultation, as well as tailored follow-up education during AF management should be initiated. Patients with mild AF-symptoms pre-consultation, tried to explain their symptoms as a consequence of age or physical deconditioning. Thereby, they did not consult their GP or considered that they had a heart disease. Previous research indicates that symptoms can be misinterpreted by patients, and by healthcare providers who dismissed symptoms as insignificant and thereby delayed diagnose and medical treatment. Instead, patients make self-care strategies such as rest, or avoiding particular activities to manage symptoms (January et al. 2014).

Patients with severe symptoms were afraid of dying during attacks and described the importance of being told by health care professionals that they were not going to die from AF. They explained that later recurrences of AF-symptoms resulted in less concern. As reported by McCabe et al. it is important for patients to find 
meaning of symptoms which are close associated to diagnosis verification and initiate AF-treatment, and by that give relief to those who had been seeking an explanation for symptoms and validation that they were not "crazy" (McCabe et al. 2011) or as stated in our study 'not going to die'.

\section{Study limitations and strengths}

First, this is a single centre study, and the number of health professionals involved was small. It would be of value to investigate several outpatient clinics for patients with $A F$ that follow such structured approach and involve a larger group of consulting health professionals.

Second, fieldwork with the presence of a researcher during consultations may in some way have influenced the behaviour of health care professionals as well as patients, and consequently may have affected how patients experienced the consultations. At the same time, the researchers' presence yielded valuable incremental information and insights over only interviewing patients. Furthermore, being present as researcher during consultations qualified the interviews, since the researcher could refer to the actual situations from the consultations and ask patients to reflect on them.

Finally, only a small number of patients were involved in the study and a larger group of informants could probably have stronger supported transferability to other settings. However the strength of this study was that all patients were referred from a GP to the outpatient clinic with newly diagnosed AF, but without a final AF-diagnosis made by the GP before first AF-clinic consultation. 


\section{CONCLUSION}

This study indicates how patients were uncertain on AF before as well as after consultation even though consultations were performed in a professional and confidential way. The communication was concentrated on the medical aspects of atrial fibrillation and visiting the clinic was an overwhelming experience. Patients had difficulty understanding why they were treated with anticoagulation, and that it was a lifelong treatment.

\section{RELEVANCE TO CLINICAL PRACITICE}

This study demonstrates some lack of patient-centred care and an absent of tailored patient AF-related education within the specialized AF-clinic. Patients were referred from the GP without preparing the patients to the AF-clinic and the professionals were not aware of these circumstances. The study highlights the actual need and importance of active patient involvement in consultations decision-making by taking into consideration patients' values and beliefs as well as knowledge about AF as a starting point.

There is a need of more knowledge of how consultations in other AF-clinic settings are performed, how consultation affects patients handling AF and how AF affects health related quality of life over time. 


\section{References}

Association WM (2013): World Medical Association Declaration of Helsinki. JAMA 310, 21912194.

Berian JR \& Livingston EH (2015): Preventing Stroke in PeopleWith Atrial Fibrillation. JAMA 314.

Bohnen M, Shea JB, Michaud GF, John R, Stevenson WG, Epstein LM, Tedrow UB, Albert C \& Koplan BA (2011): Quality of life with atrial fibrillation: do the spouses suffer as much as the patients? Pacing Clin Electrophysiol 34, 804-809.

Borg Xuereb C, Shaw RL \& Lane DA (2012): Patients' and health professionals' views and experiences of atrial fibrillation and oral-anticoagulant therapy: a qualitative metasynthesis. Patient Educ Couns 88, 330-337.

Broge C (2011): Tre gange så mange har atrieflimren i 2050 (in Danish). Hjerteforeningen, Download 22.10.12.

Butalid L, Bensing J \& Verhaak P (2014): Talking about psychosocial problems: an observational study on changes in doctor-patient communication in general practice between 1977 and 2008. Patient Educ Couns 94, 314-321.

Camm AJ, Kirchhof P, Lip GY, Schotten U, Savelieva I, Ernst S, Van Gelder IC, Al-Attar N, Hindricks G, Prendergast B, Heidbuchel H, Alfieri O, Angelini A, Atar D, Colonna P, De Caterina R, De Sutter J, Goette A, Gorenek B, Heldal M, Hohloser SH, Kolh P, Le Heuzey JY, Ponikowski P \& Rutten FH (2010): Guidelines for the management of atrial fibrillation: the Task Force for the Management of Atrial Fibrillation of the European Society of Cardiology (ESC). Eur Heart J 31, 2369-2429.

Chugh S, Havmoeller R, Narayanan K, Singh D, Rienstra M, Benjamin EJ, Gillum RF, Kim Y-H, McAnulty J, Jr., Zheng Z-J, Forouzanfar M, Naghavi M, Mensah G, Ezzati M \& Murray CJ (2014): Worldwide epidemiology of atrial fibrillation: a Global Burden of Disease 2010 Study. Circulation 129, 837-847.

Chugh SS, Blackshear JL, Shen W-K, Hammill SC \& Gersh BJ (2001): Epidemiology and natural history of atrial fibrillation: clinical implications. J Am Coll Cardiol 37, 371-378.

Conti A, Canuti E, Mariannini Y, Viviani G, Poggioni C, Boni V, Pini R, Vanni S, Padeletti L \& Gensini GF (2012): Clinical management of atrial fibrillation: early interventions, observation, and structured follow-up reduce hospitalizations. American Journal of Emergency Medicine 30, 1962-1969.

Deaton C, Dunbar SB, Moloney M, Sears SF \& Ujhelyi MR (2003): Patient experiences with atrial fibrillation and treatment with implantable atrial defibrillation therapy. Heart \& Lung: The Journal of Acute and Critical Care 32, 291-299.

Deitelzweig SB, Pinsky B, Buysman E, Lacey M, Makenbaeva D, Wiederkehr D \& Graham J (2013): Bleeding as an outcome among patients with nonvalvular atrial fibrillation in a large managed care population. ClinicalTherapeutics 35, 1536-1545 e1531.

Dreyer P \& Pedersen B (2009): Distanciation in Ricoeur's theory of interpretation: narrations in a study of life experiences of living with chronic illness and home mechanical ventilation. Nursing Inquiry 16, 64-73.

Estes NA, Sacco RL, Al-Khatib SM, Ellinor PT, Bezanson J, Alonso A, Antzelevitch C, Brockman RG, Chen PS, Chugh SS, Curtis AB, DiMarco JP, Ellenbogen KA, Epstein AE, Ezekowitz MD, Fayad P, Gage BF, Go AS, Hlatky MA, Hylek EM, Jerosch-Herold M, Konstam MA, Lee R, Packer DL, Po SS, Prystowsky EN, Redline S, Rosenberg Y, Van Wagoner DR, Wood KA, Yue L \& Benjamin EJ (2011): American Heart Association atrial fibrillation research summit: a conference report from the American Heart Association. Circulation 124, 363372. 
Fridlund B, Andersson EK, Bala S-V, Dahlman G-B, Ekwall AK, Glasdam S, Hommel A, Lindberg C, Persson El, Rantala A, Sjöström-Strand A, Wihlborg J \& Samuelson K (2015): Essentials of Teamcare in Randomized Controlled Trials of Multidisciplinary or Interdisciplinary Interventions in Somatic Care: A Systematic Review. Open Journal of Nursing 05, 10891101.

Fuster V, Ryden LE, Cannom DS, Crijns HJ, Curtis AB, Ellenbogen KA, Halperin JL, Le Heuzey JY, Kay GN, Lowe JE, Olsson SB, Prystowsky EN, Tamargo JL, Wann S, Smith SC, Jr., Jacobs AK, Adams CD, Anderson JL, Antman EM, Hunt SA, Nishimura R, Ornato JP, Page RL, Riegel B, Priori SG, Blanc JJ, Budaj A, Camm AJ, Dean V, Deckers JW, Despres C, Dickstein K, Lekakis J, McGregor K, Metra M, Morais J, Osterspey A \& Zamorano JL (2006): ACC/AHA/ESC 2006 Guidelines for the Management of Patients with Atrial Fibrillation: a report of the American College of Cardiology/American Heart Association Task Force on Practice Guidelines and the European Society of Cardiology Committee for Practice Guidelines (Writing Committee to Revise the 2001 Guidelines for the Management of Patients With Atrial Fibrillation): developed in collaboration with the European Heart Rhythm Association and the Heart Rhythm Society. Circulation 114, e257-354.

Hendriks J, de Wit R, Crijns H, Vrijhoef H, Prins M, Pisters R, Pison L, Blaauw Y \& Tieleman R (2012): Nurse-led care vs. usual care for patients with atrial fibrillation: results of a randomized trial of integrated chronic care vs. routine clinical care in ambulatory patients with atrial fibrillation. Eur Heart J ehs071 first published online March 27, 2012 doi:10.1093/eurheartj/ehs071 33, 2692-2699.

Hendriks J, Nieuwlaat R, Vrijhoef H, de Wit R, Crijns H \& Tieleman R (2010): Improving guideline adherence in the treatment of atrial fibrillation by imple menting an integrated chronic care program. Netherlands Heart Journal 18, 471-476.

Hendriks J \& Strömberg A (2015): Integrated nurse-led oral anticoagulation. CARDIOVASCULAR MEDICINE - KARDIOVASKULÄRE MEDIZIN - MÉDECINE CARDIOVASCULAIRE 18, 9-15.

January CT, Wann LS, Alpert JS, Calkins H, Cigarroa JE, Cleveland JC, Conti JB, Ellinor PT, Ezekowitz MD, Field ME, Murray KT, Sacco RL, Stevenson WG, Tchou PJ, Tracy CM \& Yancy CW (2014): 2014 AHA/ACC/HRS Guideline for the Management of Patients With Atrial Fibrillation: Executive Summary. J Am Coll Cardiol 64, 2246-2280.

Jorgensen D (1989): Participant observation. A methodology for human studies. Thousand Oaks: Sage.

Kang Y (2005): Effects of uncertainty on perceived helath status in patitents with atrial fibrillation. British Association of Critical Care Nurses, Nursing in Critical Care 10, 184-191.

Kellen J (2004): Implications for Nursing Care of Patients With Atrial Fibrillation Lessons Learned From the AFFIRM and RACE Studies. Journal of Cardiovascular Nursing 19, 128-137.

Kirchhof P, Benussi S, Kotecha D, Ahlsson A, Atar D, Casadei B, Castella M, Diener HC, Heidbuchel $\mathrm{H}$, Hendriks J, Hindricks G, Manolis AS, Oldgren J, Popescu BA, Schotten U, Van Putte B, Vardas P, Authors/Task Force M \& Document R (2016): 2016 ESC Guidelines for the management of atrial fibrillation developed in collaboration with EACTS: The Task Force for the management of atrial fibrillation of the European Society of Cardiology (ESC)Developed with the special contribution of the European Heart Rhythm Association (EHRA) of the ESCEndorsed by the European Stroke Organisation (ESO). Eur Heart J ehs071 first published online March 27, 2012 doi:10.1093/eurheartj/ehs071, 2-90.

Kleinman A, Eisenberg L \& Good B (2006): Culture, Illness, and Care: Clinical Lessons From Anthropologic and Cross-Cultural Research. THE JOURNAL OF LIFELONG LEARNING IN PSYCHIATRY 4, 140-149. 
Kodner DL \& Spreeuwenberg C (2002): Integrated care: meaning, logic, applications, and implications - a discussion paper. International Journal of Integrated Care 2, 1-6.

Kvale S (2007): Doing Interviews. SAGA.

Körner M (2010): Interprofessional teamwork in medical rehabilitation: a comparison of multidisciplinary and interdisciplinary team approach. Clinical Rehabilitation 24, 745-755.

Martin L, Williams S, Haskard K \& DiMatteo M (2005): The challenge of patient adherence. Therapeutics and Clinical Risk Management 1, 189 -199.

McCabe PJ, Rhudy LM \& DeVon HA (2014): Patients' experiences from symptom onset to initial treatment for atrial fibrillation. Journal of Clinical Nursing 24, 786-796.

McCabe PJ, Schumacher K \& Barnason SA (2011): Living with atrial fibrillation: a qualitative study. Journal of Cardiovascular Nursing 26, 336-344.

Naccarelli GV, Varker H, Lin J \& Schulman K (2009): Increasing prevalence of atrial fibrillation and flutter in the United States. America Journal of Cardiology 104, 1534-1539.

Pound P, Britten N, Morgan M, Yardley L, Pope C, Daker-White G \& Campbell R (2005): Resisting medicines: a synthesis of qualitative studies of medicine taking. Social Science \& Medicine 61, 133-155.

Reynolds MR, Essebag V, Zimetbaum P \& Cohen DJ (2007): Healthcare resource utilization and costs associated with recurrent episodes of atrial fibrillation: the FRACTAL registry. Journal of Cardiovasc Electrophysiol 18, 628-633.

Reynolds MR, Morais E \& Zimetbaum P (2010): Impact of hospitalization on health-related quality of life in atrial fibrillation patients in Canada and the United States: results from an observational registry. American Heart Journal 160, 752-758.

Rich MW (2009): Epidemiology of atrial fibrillation. Journal of Interventional Cardiac Electrophysiology 25, 3-8.

Ricoeur P (1973): The Hermeneutical Function of Distanciation. Philosophy Today 17, 129-142.

Ricoeur P (1976): Interpretation Theory - Discourse and Surplus of Meaning. Texas Christian, University Press, Forth Worth.

Ringborg A, Nieuwlaat R, Lindgren P, Jönsson B, Fidan D, Maggioni AP, Lopez-Sendon J, Stepinska J, Cokkinos DV \& Crijns HJ (2008): Costs of atrial fibrillation in five European countries: results from the Euro Heart Survey on atrial fibrillation. Europace 10, 403-411.

Sabaté E (2003): ADHERENCE TO LONG-TERM THERAPIES .Evidence for action. World Health Organization,www.adherence@who.int.

Savelieva I \& Camm J (2008): Update on atrial fibrillation: part I. Clin Cardiol 31, 55-62.

Siouta E, Muhli U, Hedberg B, Brostrom A, Fossum B \& Karlgren K (2015): Patients' experiences of communication and involvement in decision-making about atrial fibrillation treatment in consultations with nurses and physicians. Scandinavian Journal of Caring Sciences, 1-12.

Spradley J (1980): Participant Obervation. Thomson Learning, USA.

Stewart S, Murphy N, Walker A, McGuire A \& McMurray J (2004): Cost of an emerging epidemic: an economic analysis of atrial fibrillation in the UK. Heart 90, 286-292.

Ter Maten-Speksnijder AJ, Dwarswaard J, Meurs PL \& van Staa A (2016): Rhetoric or reality? What nurse practitioners do to provide self-management support in outpatient clinics: an ethnographic study. Journal of Clinical Nursing 25, 3219-3228.

Thrall G, Lane D, Carroll D \& Lip GYH (2006): Quality of life in patients with atrial fibrillation: a systematic review. The American Journal of Medicine 119, 448 e441-419.

Thrall G, Lip GYH, Carroll D \& Lane D (2007): Depression, anxiety, and quality of life in patients with atrial fibrillation. Chest 132, 1259-1264.

Tsang TSM, Petty GW, Barnes ME, O'Fallon WM, Bailey KR, Wiebers DO, Sicks JD, Christianson TJH, Seward JB \& Gersh BJ (2003): The prevalence of atrial fibrillation in incident stroke 
cases and matched population controls in Rochester, Minnesota. J Am Coll Cardiol 42, 93100.

Vestergaard A, Skjøth F, Lip G \& Larsen T (2016): Effect of Anticoagulation on Hospitalization Costs After Intracranial Hemorrhage in Atrial Fibrillation: A Registry Study. Stroke 47, 979985.

White M, Garbez R, Carroll M, Brinker E \& Howie-Esquivel J (2013): Is "teach-back" associated with knowledge retention and hospital readmission in hospitalized heart failure patients? Journal of Cardiovascular Nursing 28, 137-146.

Wise A \& Annus C (2013): Benefits of arrhythmia care coordinators. Nursign Times 109, 18-20. 


\section{Summary box}

What does this paper contribute to the wider global clinical community?

- This study included patients newly diagnosed with atrial fibrillation referred from general practitioner to an outpatient AF-clinic. The results significant some lack of patientcentred care and an absent of tailored patient AF-related education.

- There is a need of more active patient involvement in shared decision making taking patient beliefs and knowledge in consideration

- In the content of changes in global health care services more information on how outpatient clinic is managed is required. 
Table 1 Characteristics of the participants

\begin{tabular}{|c|c|c|c|c|c|}
\hline $\begin{array}{l}\text { Pseudo } \\
\text { initials }\end{array}$ & Sex & Age & $\begin{array}{l}\text { Consultations number, } \\
\text { clinicians } \\
\text { Nurses: pseudo initials }\end{array}$ & Symptoms & $\begin{array}{l}\text { Numbers of } \\
\text { consultations in } \\
\text { all }\end{array}$ \\
\hline $\mathrm{HN}$ & Female & 66 & $\begin{array}{l}\text { 1. HRS* } \\
\text { 2. Nurse C) }\end{array}$ & Intermittent. Only few symptoms & 2 \\
\hline EH & Male & 74 & $\begin{array}{l}\text { 1. HRS } \\
\text { 2. Nurse L) }\end{array}$ & $\begin{array}{l}\text { Permanent. No } \\
\text { symptoms }\end{array}$ & 2 \\
\hline AH & Female & 71 & $\begin{array}{l}\text { 1. HRS } \\
\text { 2. Nurse C) }\end{array}$ & Intermittent. Periodic palpitation & 2 \\
\hline FJ & Male & 59 & $\begin{array}{l}\text { 1. HRS } \\
\text { 2. Nurse L) } \\
\text { 3. Nurse L) }\end{array}$ & $\begin{array}{l}\text { Persistent. Periodic palpitation, } \\
\text { Dyspnoea }\end{array}$ & 3 \\
\hline JT & Male & 63 & $\begin{array}{l}\text { 1. HRS } \\
\text { 2. Nurse C) } \\
\text { 3. Nurse L) }\end{array}$ & $\begin{array}{l}\text { Permanent. Few periods with } \\
\text { dyspnoea }\end{array}$ & 3 \\
\hline$A D$ & Female & 77 & $\begin{array}{l}\text { 1. HRS } \\
\text { 2. Nurse C) }\end{array}$ & Permanent. No symptoms & 2 \\
\hline IC & Female & 67 & $\begin{array}{l}\text { 1. HRS } \\
\text { 2. Nurse C) }\end{array}$ & Permanent. Fatigue & 2 \\
\hline $\mathrm{NH}$ & Male & 67 & $\begin{array}{l}\text { 1. HRS } \\
\text { 2. Nurse C) } \\
\text { 3. Nurse L) }\end{array}$ & Permanent. No symptoms & 3 \\
\hline$J P$ & Female & 70 & $\begin{array}{l}\text { 1. HRS } \\
\text { 2. Nurse L) } \\
\text { 3. Nurse C) } \\
\text { 4. Nurse C) }\end{array}$ & $\begin{array}{l}\text { Permanent. dyspnoea, some } \\
\text { Palpitation }\end{array}$ & 4 \\
\hline $\mathrm{KL}$ & Male & 79 & $\begin{array}{l}\text { 1. HRS } \\
\text { 2. Nurse L) } \\
\text { 3. Nurse C) } \\
\text { 4. Nurse L) } \\
\text { 5. Nurse C) }\end{array}$ & $\begin{array}{l}\text { Permanent. Periods with } \\
\text { palpitation }\end{array}$ & 5 \\
\hline JH & Male & 40 & $\begin{array}{l}\text { 1. HRS, } \\
\text { 2. Nurse C) } \\
\text { 3. Nurse C) }\end{array}$ & Intermittent. Dyspnoea, palpitation & 3 \\
\hline MC & Female & 82 & $\begin{array}{l}\text { 1. HRS } \\
\text { 2. Nurse C) } \\
\text { 3. Nurse C) } \\
\text { 4. Nurse L) } \\
\text { 5. Nurse L) }\end{array}$ & Permanent. dyspnoea, fatigue & 5 \\
\hline IL & Female & 70 & $\begin{array}{l}\text { 1. HRS } \\
\text { 2. Nurse C) } \\
\text { 3. Nurse L) }\end{array}$ & $\begin{array}{l}\text { Intermittent. Few periods with } \\
\text { palpitation }\end{array}$ & 3 \\
\hline$J A$ & Male & 71 & $\begin{array}{l}\text { 1. HRS } \\
\text { 2. Nurse C) } \\
\text { 3. Nurse C) }\end{array}$ & Intermittent. Palpitation, fatigue & 3 \\
\hline
\end{tabular}

* HRS $=$ Heart Rhythm Specialist 
Table 2 Units of meaning, units of significance and main theme: "Visiting the clinic - an overwhelming experience"

\begin{tabular}{lll}
\hline Units of meaning & Units of significance & Subthemes \\
(What the text is saying) & (What the text speaks about) & \\
\hline
\end{tabular}

$\mathrm{HN}$ : "After the first consultation we did not know much more

Difficult to understand information

- information during consultation

about the name of the game. No, I do not think so. I did a google

search afterwards and know where I can find more."

After consultation: $\mathrm{NH}$ : "I need to go to my general practitioner and hope, that he can explain my what kind of disease I have and what Is going to happen."

JA: "No - I cannot tell you what atrial fibrillation is and why I am medical treated as I am. (Pause) I really do not understand

Difficult to describe AF and treatment

- knowledge after consultations are

what kind of disease I have. But I do take the medicine as prescribed" 
Table 3 Results Themes and subthemes

Themes

Uncertainty about the atrial fibrillation before first consultation

Focus on the medical aspects of atrial fibrillation

Atrial fibrillation is no fatal disease

of atrial fibrillation

Visiting the clinic - an overwhelming experience

\section{Subthemes}

Pre-consultation knowledge

Beginning consultation with medical examination

Not knowing what to ask for

Metaphors

Fear of dying

Crucial information

Confidence inspiring way

Taking time

Precondition before consultation Information during consultation

Knowledge after consultations ended 